\title{
A (DES)IGUALDADE DE CONHECIMENTO INTRAESCOLAR
}

\author{
http://dx.doi.org/10.5902/2318133866803
}

\author{
Naira da Costa Muylaert Lima ${ }^{1}$
}

\begin{abstract}
Resumo
Neste texto apresenta-se resultado de trabalho que teve como objetivo investigar a (re)produção de desigualdades de aprendizagem no interior de uma escola pública do Estado do Espírito Santo. Com base numa abordagem metodológica quanti-quali, o estudo investigou a variação das médias de desempenho em Língua Portuguesa no Paebes-Alfa das turmas da escola Tulipa. Identificouse que, dentre as quatros turmas, uma ficou com desempenho significativamente menor que as outras três, revelando desigualdades de conhecimento intraescolar. Esse desempenho inferior pode ser explicado por algumas características observadas na turma como, por exemplo, o não cumprimento do currículo planejado, a alocação de uma professora com pouca experiência e com vínculo empregatício instável e a concentração de alunos com algum tipo de deficiência.

Palavras-chave: igualdade de conhecimento; eficácia escolar; alfabetização; avaliação em larga escala.
\end{abstract}

\section{THE (IN)EQUALITY OF KNOWLEDGE INSIDE THE SCHOOL}

\begin{abstract}
This work aims to investigate the (re)production of learning inequalities within a public school in the State of Espírito Santo. Based on a quanti-quali approach, the study investigated the performance variation in Portuguese in the Paebes-Alfa of the Tulipa school classes and identified that, among the four classes, one performed significantly lower than the other three, revealing the inequality of knowledge. This performance can be explained by some characteristics observed in this class, such as non-compliance with the planned curriculum, the allocation of a teacher with little experience and unstable employment relationship, and the concentration of students with some type of disability.

Key-word: equality of knowledge; school effectiveness; literacy; large-scale evaluation.
\end{abstract}

${ }^{1}$ Pontifícia Universidade Católica do Rio de Janeiro, Brasil. E-mail: naira@puc-rio.br. 


\section{Introdução}

A s desigualdades educacionais, em termos de resultados escolares, podem $\triangle$ ser encontradas em diversos níveis como, por exemplo, entre regiões geográficas, Estados, municípios, redes de ensino, escolas da mesma rede, turmas da mesma escola e alunos da mesma turma. As variações nos resultados dos alunos são esperadas, pois os indivíduos não são iguais entre si e cada um tem características específicas - condição socioeconômica, cor/raça, gênero, disposições cognitivas, etc. - que podem explicar, em parte, as diferenças de desempenho escolar. Porém, nos outros níveis, como o da rede de ensino, das escolas e das turmas, essas variações são explicadas não apenas pelas características de cada um, mas também por outros aspectos que remetem ao tema da relação entre desigualdade social e desigualdade escolar.

Desde o Relatório Coleman inúmeros estudos no campo da eficácia escolar e da Sociologia da Educação são desenvolvidos em vários países com o objetivo de investigar o efeito das características escolares no desempenho dos alunos e, de forma mais específica, na variação do desempenho, numa tentativa de compreender os fatores escolares que incidem sobre a (re)produção das desigualdades. Alinhado a esses estudos o presente trabalho tem como objetivo principal investigar a (des)igualdade de conhecimento (Crahay, 2002) nos três primeiros anos do ciclo de alfabetização a partir de uma metodologia quanti-quali. Num primeiro momento, de abordagem quantitativa, foram utilizados os dados das edições de 2012, 2013 e 2014 do Programa de Avaliação da Educação Básica do Espírito Santo voltado para a alfabetização - Paebes-Alfa - para verificar a desigualdade do desempenho em Língua Portuguesa entre as turmas de uma mesma escola. No segundo momento, por meio de uma abordagem qualitativa, buscouse compreender as variações dos resultados entre as turmas, por meio do levantamento de fatores escolares que podem ajudar a explicar tais variações e, consequentemente, a (des)igualdade de conhecimento intraescolar.

\section{A (des)igualdade de conhecimento}

A discussão da justiça na educação pode ser abordada à luz de três perspectivas: igualdade de oportunidade, de tratamento e de conhecimento. Há tempo as duas primeiras perspectivas são debatidas em estudos do campo da Sociologia da Educação, que relaciona desigualdades educacionais e desigualdades sociais. Crahay (2002), ao refletir sobre a justiça no âmbito da educação básica, mostra os limites das duas noções e apresenta o conceito de igualdade de conhecimento como um elemento imprescindível para a promoção de uma escola justa.

Para o autor uma escola só é capaz de promover justiça e combater eficazmente a desigualdade quando consegue garantir o aprendizado de conhecimentos essenciais a todos os estudantes. Isso significa que o ensino deve ser organizado e planejado em função de objetivos que devem ser atingidos por todos e, por isso, as várias formas de organização escolar devem ter como foco o aprendizado. Para Crahay (2002) é preciso reconhecer que cada indivíduo possui ritmos e formas diferentes de aprendizagem e, por isso, a escola deve lançar mão de diversas estratégias de ensino para garantir que o 
aprendizado seja alcançado por todos. Uma dessas estratégias, ressalta o autor, é uma dedicação suplementar de tempo aos estudantes que não conseguiram consolidar os conhecimentos de base: aqueles considerados fundamentais para a formação do cidadão e que por isso não podem deixar de ser ensinados.

Para Ribeiro (2012) a garantia da igualdade de conhecimento acontece por meio de um conjunto de ações pedagógicas comprometidas com princípios de justiça que visam a garantir direitos, tais como 0

reforço escolar para crianças com dificuldade de aprendizagem, aulas com diversidade de práticas pedagógicas para crianças com diferentes níveis de aprendizagem, inexistência de reprovação associada a baixos desempenhos e baixa desigualdade escolar e professores mais experientes trabalhando com crianças com maiores dificuldades naquele momento. Salas heterogêneas (constituídas por alunos com maiores facilidades e dificuldades no momento), estratégias de ensino coletivas e não pautadas pela individualização da aprendizagem e foco nos objetivos de aprendizagem. (Ribeiro, 2012 p.106)

Nesse sentido, uma escola que se pretende justa precisa adotar ações pedagógicas ancoradas no princípio da igualdade de conhecimento para garantir o aprendizado de todos e tornar a variação dos desempenhos escolares a menor possível. Essas ações se alinham à ideia de discriminação positiva (Perrenoud, 1995, apud Crahay, 2002), pois buscam favorecer os desfavorecidos e, por isso, tendem a reduzir as desigualdades.

A discriminação positiva consiste na tomada de consciência das desigualdades e nas ações implantadas com o objetivo de compensá-las. Uma das premissas da discriminação positiva é evitar a formação de guetos de cultura, dinheiro e qualidade e de guetos de pobreza e dificuldades. Tanto dentro da rede privada, quanto dentro da rede pública de ensino existem mecanismos de mercados escolares (Dubet, 2004a), ou seja, escolas fortes e escolas fracas. Uma das maneiras de se resistir à formação de escolas guetos é introduzir mecanismos compensatórios centrados nos alunos.

Desta forma, a busca por uma escola justa consiste na adoção de ações de discriminação positiva, ou seja, de ações pedagógicas destinadas a grupos de estudantes com dificuldades, de forma a garantir que os conhecimentos de base sejam aprendidos por todos.

As avaliações em larga escala vêm evidenciando, recorrentemente, lacunas no aprendizado dos conhecimentos de base dos estudantes. Os dados do Saeb/Prova Brasil, bem como os dados das avaliações estaduais, realizadas com alunos do $5^{\circ}$ e do $9^{\circ}$ ano do ensino fundamental, mostram que há uma grande dificuldade de se alcançar níveis satisfatórios de aprendizado para as duas disciplinas avaliadas: Português com ênfase em leitura e Matemática com ênfase na resolução de problemas. A falta de um diagnóstico sobre o momento e a natureza das dificuldades encontradas na aprendizagem das habilidades básicas deve-se, em parte, à ausência de testes nos anos anteriores ao $5^{\circ}$ ano e está na origem das avaliações da alfabetização implementadas em alguns Estados brasileiros, como o Espírito Santo e, também, no Estudo Longitudinal da Geração Escolar 2005 - Geres².

2 Para mais informações, acessar: https://www.laedpuc.net.br/projeto-geres. 
A compreensão de que os resultados insatisfatórios dos alunos são decorrentes de uma defasagem acumulada de conhecimentos e habilidades desde o início da alfabetização, levou o governo federal, Estados e municípios a adotar uma série de medidas, como a ampliação da duração do ensino fundamental para nove anos, lei $\mathrm{n}$. 11.274/06, a criação do Pacto Nacional pela Alfabetização na Idade Certa - Pnaic - e a incorporação da Avaliação Nacional da Alfabetização ao Saeb no ano de $2013^{3}$.

No âmbito dos Estados e dos municípios muitos possuem políticas próprias voltadas para a etapa da alfabetização. Pode-se destacar, por exemplo, os Estados de Minas Gerais, Ceará e Espírito Santo que elaboraram seus próprios sistemas de avaliação da avaliação antes mesmo do governo federal criar a ANA. Além de avaliar os mesmos anos escolares que o Saeb - 5 e $9^{\circ}$ anos -, esses Estados avaliam também as etapas referentes aos anos iniciais do ensino fundamental.

O Espírito Santo implantou seu sistema de avaliação da alfabetização em 2008, por meio da aplicação de testes de leitura, escrita e Matemática aos alunos dos três primeiros anos do ensino fundamental. Possui características inovadoras que o diferencia das avaliações implantadas nos demais Estados, ofertando dados mais precisos sobre as redes de ensino, as escolas e os alunos. A primeira inovação refere-se à inclusão de itens de escrita nas provas e a segunda refere-se ao desenho longitudinal do Paebes-Alfa, que permite verificar o valor agregado ao desempenho dos alunos ao longo dos três anos do ciclo de alfabetização. Tal desenho permite a elaboração de estudos mais acurados sobre o tema das desigualdades educacionais. São essas duas inovações que justificam a escolha do Paebes-Alfa para a investigação do tema das desigualdades entre as escolas e dentro das escolas nos anos iniciais do ensino fundamental, etapa escolar imprescindível para o aprendizado dos conhecimentos de base (Crahay, 2002).

\section{Metodologia}

Para se alcançar os objetivos do estudo fez-se uso de uma abordagem metodológica quanti-quali. No primeiro momento, com metodologia quantitativa, fez-se um estudo sobre o valor agregado ao aprendizado dos alunos que participaram do PaebesAlfa para a seleção da escola a ser investigada. Em seguida, após a seleção da escola, o estudo se debruçou sobre a análise da variação dos dados de proficiência em língua Portuguesa entre as turmas da escola selecionada. No terceiro momento da pesquisa realizou-se uma investigação qualitativa, por meio de entrevistas e observações, momento em que se buscou compreender os resultados de variação do desempenho no Paebes-Alfa por meio da coleta de informações sobre os principais fatores escolares reportados pela literatura (Brooke; Soares, 2008) que contribuem para o aprendizado dos alunos.

\footnotetext{
${ }^{3}$ Em 2016 a ANA foi interrompida e, em 2019, foi retomada no âmbito do Saeb com nova metodologia. 


\section{A seleção da escola}

Para selecionar a escola observamos a evolução do desempenho e do valor agregado no seguinte corte temporal $4^{4} 1^{\underline{a}}$ medida: início do $1^{\circ}$ ano (2012); $2^{\underline{a}}$ medida: final do $1^{\circ}$ ano (2012); $3^{a}$ medida: final do $2^{\circ}$ ano (2013).

As medidas de leitura e escrita possuem escalas de desempenho diferentes, mas que podem ser agregadas de forma a criar uma medida de Língua Portuguesa, abarcando, numa mesma escala, as duas dimensões da alfabetização. A medida de Língua Portuguesa foi utilizada para a seleção das escolas, ao passo que as medidas de leitura e escrita foram utilizadas, separadamente, para a análise da evolução e variação dos desempenhos entre as turmas. Seis critérios foram utilizados: participação na avaliação de 2012 (1ํano: entrada e saída) e 2013 (2º ano: saída); mínimo de duas turmas; rede pública de ensino; valor agregado ${ }^{5}$ em termos de média de desempenho no Paebes-Alfa; alteração de quartil entre as três avaliações ${ }^{6}$; localização geográfica. Com base nos primeiros cinco critérios foram criados clusters, cuja finalidade foi criar perfis de escolas segundo suas características, conforme apresenta o quadro 1.

Quadro 1 -

Descrição das características das escolas nos clusters.

\begin{tabular}{|c|c|c|c|l|}
\hline Cluster & Rede & $\begin{array}{c}\text { Valor Agregado } \\
\text { (período 1) }\end{array}$ & $\begin{array}{l}\text { Valor agregado } \\
\text { (Período 2) }\end{array}$ & \multicolumn{1}{|c|}{ Quartil } \\
\hline 1 & Municipal & VA positivo & VA positivo & $\begin{array}{l}\text { Escolas que se situaram no quartil 1 nas } \\
\text { três avaliações }\end{array}$ \\
\hline 2 & Municipal & VA positivo & VA positivo & $\begin{array}{l}\text { Escolas que se situaram no quartil 4 nas } \\
\text { três avaliações }\end{array}$ \\
\hline 3 & $\begin{array}{l}\text { Municipal } \\
\text { e estadual }\end{array}$ & VA negativo & VA negativo & $\begin{array}{l}\text { Escolas que estavam no quartil 4 nas } \\
\text { avaliações de entrada e saída de 2012 e } \\
\text { caíram de quartil na avaliação de 2013. }\end{array}$ \\
\hline 5 & Municipal & VA positivo & VA positivo & $\begin{array}{l}\text { Escolas que se situavam no quartil 4 na } \\
\text { avaliação de entrada em 2012. Algumas } \\
\text { permaneceram no quartil 4 nas outras } \\
\text { duas avaliações e algumas caíram } \\
\text { progressivamente de quartil ao longo } \\
\text { das outras duas. }\end{array}$ \\
\hline & VA positivo & VA positivo & $\begin{array}{l}\text { Escolas que estavam em diferentes } \\
\text { quartis na entrada de 2012 e que } \\
\text { mudaram de quartil ao longo das outras }\end{array}$ \\
\hline
\end{tabular}

${ }^{4}$ Os dados de 2014, referentes ao $3^{\circ}$ ano do ensino fundamental, não foram considerados, pois a seleção das escolas para a coleta dos dados qualitativos foi realizada em setembro daquele ano, antes da aplicação da avaliação que aconteceu no mês de novembro.

5 O cálculo do valor agregado foi realizado para dois períodos diferentes: Período 1: desempenho na saída em 2012 - desempenho na entrada em 2012; Período 2: desempenho na saída em 2013 - desempenho na saída em 2012.

6 Para atender esse critério, analisou-se quais escolas mudaram, ou não, de quartil. As médias de desempenho foram divididas em quartis, de forma que o quartil 1 agrupa as médias de desempenho mais baixas; o quartil 4 agrupa as médias de desempenho mais altas; e os quartis 2 e 3 agrupam as médias de desempenho medianas. $O$ objetivo foi verificar se as médias tiveram expressiva variação que permitiu a mudança de quartil entre as avaliações.

Regae: Rev. Gest. Aval. Educ. $\quad$ Santa Maria

v. 10

ก. 19

e66803, p. 1-17

2021 


\begin{tabular}{|c|c|c|l|l|} 
& & & $\begin{array}{l}\text { duas avaliações, ou para cima ou para } \\
\text { baixo. }\end{array}$ \\
\hline 6 & Municipal & VA Positivo & VA positivo & $\begin{array}{l}\text { Escolas que se situavam no quartil 1 ou } \\
2 \text { na entrada de 2012 e mudaram de } \\
\text { quartil nas outras duas avaliações, } \\
\text { sempre para cima. }\end{array}$ \\
\hline 7 & $\begin{array}{l}\text { Municipal } \\
\text { e estadual }\end{array}$ & VA positivo & VA positivo & $\begin{array}{l}\text { Escolas que se situavam no quartil 1 na } \\
\text { entrada de 2012. Algumas } \\
\text { permaneceram no quartil 1 nas outras } \\
\text { duas avaliações e algumas mudaram de } \\
\text { quartil para cima. }\end{array}$ \\
\hline 8 & $\begin{array}{l}\text { Municipal, } \\
\text { estadual e } \\
\text { particular }\end{array}$ & VA positivo & VA negativo & $\begin{array}{l}\text { Escolas que se situavam no quartil 4 } \\
\text { nas três avaliações. }\end{array}$ \\
\hline
\end{tabular}

Fonte: dados do Paebes-Alfa.

Após esta etapa eliminou-se as escolas particulares por não serem o escopo da investigação e mais um filtro com dois critérios foram estipulados: escolas que permaneceram nas três avaliações nos quartis 1 e 4 - escolas que agregaram pouco ou nenhum valor, pois a variação do desempenho foi pequena e não permitiu a mudança de quartil -; escolas que aumentaram ou diminuíram significativamente o desempenho e conseguiram mudar de quartil, para cima ou para baixo.

Por fim, considerando todos esses critérios, selecionou-se a escola Tulipa ${ }^{7}$ por agregar muito valor ao aprendizado de uma avaliação para outra, de forma a mudar sempre de quartil para cima. Com isso, pode-se considerar que é uma escola que promove eficácia, ou seja, faz aumentar significativamente o desempenho médio de seus estudantes. Além disso, a escola Tulipa localiza-se em Cariacica, município da região metropolitana de Vitória, com relativa facilidade de acesso.

A partir desta seleção o estudo se debruçou sobre a análise da (des)igualdade de conhecimento (Crahay, 2002) a partir de duas abordagens: uma de caráter quantitativo, que analisou a variação do desempenho entre as turmas, e a outra de caráter qualitativo que analisou algumas características escolares (Sammons, Hillman, Mortimore, 1995) associadas ao aprendizado dos alunos.

\section{A escola Tulipa}

Localizada no município de Cariacica, a escola Tulipa possuía, em 2014, quatro turmas no $3^{\circ}$ ano do ensino fundamental: duas no turno da manhã, turmas $A$ e $B$, e duas no turno da tarde, turmas C e D. Segundo os dados do Paebes-Alfa a escola aumentou suas médias de desempenho ao longo das quatro avaliações e finalizou o ciclo de alfabetização com padrão de desempenho proficiente em leitura e em escrita. No quadro 2 apresenta-se a evolução da média de proficiência e o padrão de desempenho ao longo dos três primeiros anos do ciclo de alfabetização.

\footnotetext{
7 Nome fictício.
} 
Quadro 2 -

Desempenho e padrão de desempenho da escola Tulipa por avaliação

\begin{tabular}{|l|c|c|c|c|c|c|c|c|}
\hline \multicolumn{1}{|c|}{$\begin{array}{c}\text { Domínio da } \\
\text { Língua } \\
\text { Portuguesa }\end{array}$} & \multicolumn{9}{|c|}{ Leitura } & \multicolumn{4}{c|}{ Escrita } \\
\hline Avaliação & Av 1 & Av 2 & Av 3 & Av 4 & Av 1 & Av 2 & Av 3 & Av 4 \\
\hline $\begin{array}{l}\text { Desempenho } \\
\text { médio }\end{array}$ & 395,0 & 552,8 & 651,5 & 743,0 & 385,2 & 571,1 & 662,6 & 678,9 \\
\hline $\begin{array}{l}\text { Padrão de } \\
\text { desempenho }\end{array}$ & $\begin{array}{c}\text { Abaixo } \\
\text { do } \\
\text { básico }\end{array}$ & $\begin{array}{c}\text { Profici- } \\
\text { ente }\end{array}$ & $\begin{array}{c}\text { Profici- } \\
\text { ente }\end{array}$ & $\begin{array}{c}\text { Profici- } \\
\text { ente }\end{array}$ & $\begin{array}{c}\text { Abaixo } \\
\text { do } \\
\text { básico }\end{array}$ & $\begin{array}{c}\text { Proficie } \\
\text {-nte }\end{array}$ & $\begin{array}{c}\text { Profici- } \\
\text { ente }\end{array}$ & $\begin{array}{c}\text { Profici- } \\
\text { ente }\end{array}$ \\
\hline
\end{tabular}

Fonte: dados do Paebes-Alfa.

Pela análise pode-se verificar que a escola sempre aumenta sua média de desempenho nas duas dimensões da alfabetização, indicando, portanto, que a escola agrega valor ao aprendizado dos alunos ao longo do ciclo de alfabetização. Importa destacar que o maior ganho acontece, tanto em leitura, quanto em escrita, entre a entrada (Av 1) e a saída (Av 2) do $1^{\circ}$ ano do ensino fundamental, revelando a importância da escola no primeiro ano do ciclo de alfabetização. Apesar disso a análise da evolução da média das turmas da escola Tulipa permitiu observar variações muito significativas, o que fez com que as turmas alcançassem padrões de desempenho diferenciados, revelando desigualdades de conhecimento intraescolar.

No quadro 3 mostra-se que as quatro turmas ${ }^{8}$ da escola Tulipa obtiveram, na primeira avaliação, um desempenho médio em leitura insatisfatório, abaixo do básico e básico. As turmas $\mathrm{B}$ e $\mathrm{C}$ mantiveram um aumento progressivo das suas médias, finalizando o ciclo de alfabetização com aprendizado satisfatório: proficiente na turma $\mathrm{B}$ e avançado na turma C. A turma D, que teve um nível avançado no final do $1^{\circ}$ ano, apresentou uma queda expressiva de sua média de proficiência no final do $2^{\circ}$ ano, ficando no nível básico. Apesar disso, no $3^{\circ}$ ano, a média melhorou bastante e a turma ficou no nível avançado. Já a turma $A$ teve uma queda de proficiência no $3^{\circ}$ ano e finalizou o ciclo de alfabetização no nível de desempenho abaixo do básico.

Quadro 3 -

Desempenho médio e padrão de desempenho em Leitura das turmas da escola Tulipa nas quatro ondas de avaliação do Paebes-Alfa.

\begin{tabular}{|c|c|c|c|c|c|c|c|c|}
\hline Turma & Av 1 & $\begin{array}{c}\text { Padrão de } \\
\text { desempe- } \\
\text { nho }\end{array}$ & Av 2 & $\begin{array}{c}\text { Padrão de } \\
\text { desempe- } \\
\text { nho }\end{array}$ & Av 3 & $\begin{array}{c}\text { Padrão de } \\
\text { desempenho }\end{array}$ & Av 4 & $\begin{array}{c}\text { Padrão de } \\
\text { desempenho }\end{array}$ \\
\hline Turma A & 325,2 & $\begin{array}{c}\text { Abaixo do } \\
\text { básico }\end{array}$ & 514,92 & Proficiente & 602,11 & Proficiente & 589,46 & $\begin{array}{c}\text { Abaixo do } \\
\text { básico }\end{array}$ \\
\hline Turma B & 409,4 & Básico & 558,47 & Proficiente & 643,27 & Proficiente & 744,37 & Proficiente \\
\hline
\end{tabular}

${ }^{8}$ A análise da evolução das turmas não se configura como longitudinal pois as turmas mudam de um ano para o outro. Ou seja, os agrupamentos estudantis se modificam durante o período em análise. 


\begin{tabular}{|l|c|c|c|c|c|c|c|c|}
\hline Turma C & 368,69 & $\begin{array}{c}\text { Abaixo do } \\
\text { básico }\end{array}$ & 522,39 & Proficiente & 680,13 & Proficiente & 760,45 & Avançado \\
\hline Turma D & 479,84 & Básico & 633,34 & Avançado & 504,85 & Proficiente & 756,71 & Avançado \\
\hline
\end{tabular}

Fonte: dados do Paebes-Alfa.

Os dados não permitem explicar a trajetória do desempenho de cada turma mas, a partir dos dados coletados nas observações e entrevistas, é possível levantar algumas hipóteses que ajudam a compreender os resultados obtidos pelas turmas no $3^{\circ}$ ano do ensino fundamental. Uma possível explicação para o resultado insatisfatório da turma $A$ pode ser associado à distribuição dos professores nas turmas, pois a professora da turma A era a única contratada e que possuía menos tempo de experiência, enquanto as outras três professoras eram efetivas, com maior tempo de magistério e sempre lecionaram para as turmas do $3^{0}$ ano do ensino fundamental. A alocação dos docentes nas turmas era feita pela diretora, de acordo com o perfil de cada docente. Na entrevista, ela afirmou que matinha as mesmas professoras nas turmas $\mathrm{C}$ e $\mathrm{D}$, pois elas tinham o perfil do $3^{\circ}$ ano. Além disso, todos os alunos do $3^{\circ}$ ano que apresentaram alguma dificuldade de aprendizagem ou laudo médico estavam na turma $A$, incluindo um menino diagnosticado com esquizofrenia.

O que se observa, ainda, a partir dos dados do quadro 3 , é que há uma variação significativa do desempenho entre o início e o fim do $1^{\circ}$ ano e que essa variação vai diminuindo ao longo do tempo. Com isso, no final do $3^{\circ}$ ano, as turmas $B, C$ e D apresentaram praticamente a mesma média, enquanto a turma $A$ se distanciou da média das outras três. Isso significa que as turmas B, C e D se tornaram mais homogêneas em termos de aprendizagem ao longo desse período.

Numa análise mais geral, ao final do ciclo de alfabetização os alunos da turma $A$ apresentaram um prejuízo pedagógico no domínio da leitura em comparação com as outras turmas, que se expressa na falta de aprendizagem ou na aprendizagem insatisfatória de certas habilidades como, por exemplo, a habilidade de identificar 0 conflito gerador da narrativa, a dificuldade de reconhecer o locutor de um texto de curta extensão, ou para inferir o assunto do texto a partir do seu título. Além disso ainda não são plenamente capazes de reconhecer o humor num texto e o efeito de sentido produzido pelo uso de onomatopeias em poesias. Estas habilidades, dentre outras, não foram plenamente consolidadas pelos alunos da turma $A$, ao passo que os alunos das demais turmas já estavam alfabetizados, segundo a interpretação pedagógica da escala de proficiência do Paebes-Alfa.

No que diz respeito à Escrita, o quadro 4 mostra que a variação da média da proficiência na entrada $(A \vee 1)$ e saída $(A \vee 2)$ do $1^{\circ}$ ano é baixa, sendo que, entre essas duas avaliações, a turma $\mathrm{C}$ obteve o maior ganho. No $2^{\circ}$ ano a variação das médias aumentou significativamente: a turma B alcançou o nível avançado, as turmas A e C ficaram no nível proficiente e a turma $D$, que teve uma queda da média, ficou no nível básico. No final do $3^{\circ}$ ano a variação da proficiência foi um pouco maior que no início do ciclo de alfabetização, gerando heterogeneidade do aprendizado: enquanto as turmas D e B possuíam médias de proficiência próximas e situavam-se no nível proficiente, as turmas A e $\mathrm{C}$, que também possuíam médias próximas, situavam-se no nível básico. Com isso pode-se considerar que os estudantes das turmas A e C possuíam uma defasagem de 
conhecimento em comparação aos estudantes das turmas $D$ e $B$, uma vez que eles demostraram dominar habilidades ainda não plenamente consolidadas pelos alunos das turmas $\mathrm{A}$ e $\mathrm{C}$. Por exemplo, as habilidades referentes à escrita de palavras com dígrafos, marcas de nasalização e irregularidades ortográficos como o uso do "s"/“z"; "s"/"c"; "x"/“ch"; "g"/“j"; "ss"/"ç"; e também aos problemas de hipossegmentação - quando o aprendiz junta uma palavra na outra em uma frase ou texto -, bem como à produção de textos de gêneros diferenciados com proposições comunicativas, como o bilhete e 0 convite, ainda não foram plenamente consolidados por esses estudantes, ao passo que seus colegas das turmas $D$ e B já dominavam tais habilidades.

Quadro 4 -

Desempenho médio e padrão de desempenho em Escrita das turmas da escola Tulipa nas quatro ondas de avaliação do Paebes-Alfa.

\begin{tabular}{|c|c|c|c|c|c|c|c|c|}
\hline Turma & Av 1 & $\begin{array}{c}\text { Padrão de } \\
\text { desempe- } \\
\text { nho }\end{array}$ & Av 2 & $\begin{array}{c}\text { Padrão de } \\
\text { desempe- } \\
\text { nho }\end{array}$ & Av 3 & $\begin{array}{c}\text { Padrão de } \\
\text { desempenho }\end{array}$ & Av 4 & $\begin{array}{c}\text { Padrão de } \\
\text { desempenho }\end{array}$ \\
\hline Turma A & 384,2 & $\begin{array}{c}\text { Abaixo do } \\
\text { básico }\end{array}$ & 580 & Proficiente & 677,26 & Proficiente & 645,58 & Básico \\
\hline Turma B & 422,7 & Básico & 534,73 & Proficiente & 728,71 & Avançado & 705,44 & Proficiente \\
\hline Turma C & 357,23 & $\begin{array}{c}\text { Abaixo do } \\
\text { básico }\end{array}$ & 590,67 & Proficiente & 641,8 & Proficiente & 641,03 & Básico \\
\hline Turma D & 404,16 & Básico & 562,61 & Proficiente & 549,55 & Básico & 713,12 & Proficiente \\
\hline
\end{tabular}

Fonte: dados do Paebes-Alfa.

Pode-se perceber, portanto, que os estudantes da escola Tulipa finalizaram o ciclo de alfabetização com níveis diferenciados de aprendizado em leitura e em escrita, o que significa que havia desigualdade na aquisição dos conhecimentos de base (Crahay, 2002) no interior da escola. Algumas características escolares podem ajudar a compreender esta variação nas médias de proficiência das turmas da escola Tulipa.

\section{As características escolares}

A realização de observações e entrevistas, permitiu a coleta de algumas características da escola e das turmas, identificadas pela literatura (Crahay, 2002; Oliveira et al, 2013; Slavin, 1996; Sammons, Hillman, Mortimore, 1995; Murillo, 2003) como fatores de eficácia escolar (Brooke; Soares, 2008). São elas: cumprimento do currículo; responsabilidade pelo aprendizado dos alunos; não absenteísmo docente; colaboração docente; organização das turmas; qualidade docente: formação e distribuição; uso do tempo; participação e envolvimento dos pais nas atividades escolares dos filhos.

\section{Cumprimento do currículo}

O cumprimento do currículo é uma categoria de análise reportada pela literatura como um fator que influencia positivamente a aprendizagem. $O$ planejamento das aulas com base no currículo definido pela escola ou rede de ensino, de forma a cumprir toda a extensão do conteúdo, tem um efeito positivo no desempenho dos alunos e é apontado como um dos aspectos das escolas eficazes (Brooke; Soares, 2008) 
Os pedagogos da escola Tulipa afirmaram que o currículo trabalhado na escola é definido com base no currículo estabelecido pela Secretaria Municipal de Educação, nos parâmetros curriculares nacionais ${ }^{9}$ e nos livros didáticos. Eles não souberam dizer exatamente quanto tempo da carga horária escolar é dedicada a cada matéria, mas afirmaram que um maior tempo de aula é dedicado a Português e Matemática. Apesar disso, nesta escola, apenas uma professora afirmou completar $100 \%$ do planejamento curricular. As demais afirmaram não conseguir cumprir o planejamento até o final do ano letivo, sendo que a professora da turma A garantiu cumprir apenas $70 \%$ do conteúdo programado.

Das quatro professoras do $3^{\circ}$ ano ela é a única DT, termo que significa designação temporária e que se refere aos professores contratados. Durante a entrevista essa professora se queixou da direção da escola e dos demais colegas, afirmando que recebe um tratamento desigual justamente por ser DT. Disse que participa presencialmente, mas não tem voz na construção do projeto político-pedagógico da escola. Por mais de uma vez, durante a entrevista, disse que todos os "pepinos" caem na mão dela, fazendo referência ao aluno esquizofrênico que pertence à sua turma e que tem uma mediadora que o acompanha de forma não regular.

Nas aulas observadas essa professora trabalhou com a confecção de material reciclado. A partir de garrafas pet, os alunos produziriam um puf que seria apresentado na amostra cultural ${ }^{10}$. A aula observada tratou de atividades lúdicas, que exercitavam a criatividade e a coordenação motora, uma vez que exigiam o manuseio de materiais: corte, colagem e pintura das garrafas e, também, raciocínio lógico, pois os alunos precisaram pensar como deveriam encaixar as garrafas para formar o puf. Essa aula abordou o tema da reciclagem, relacionado ao tema do meio ambiente, que, segundo a professora, vinha sendo trabalhado desde o início do ano. Além disso, durante a aula, a professora trabalhou contas de adição e subtração rapidamente e sem grau de dificuldade elevado, com o objetivo de mostrar aos alunos como encaixar uma garrafa na outra para montar o puf.

Nas demais aulas as atividades referentes à amostra cultural não foram observadas. Nas demais turmas observou-se apenas aulas tradicionais e os conteúdos mais trabalhados foram, de fato, Português e Matemática, e em todas as aulas as professoras utilizaram os materiais didáticos tradicionais: livros didáticos, cópia do quadro e folhinhas de exercícios.

\section{Responsabilidade pelo aprendizado dos alunos}

O sentimento de responsabilidade pelo aprendizado é frequentemente reportado pela literatura em eficácia escolar como um dos fatores associados a um bom desempenho cognitivo nos testes em larga escala, como mostram os estudos de Espósito, Davis e Nunes (2000), Albernaz, Ferreira e Franco (2002) e Lee, Franco e Albernaz (2007) e Alves e Franco (2008).

\footnotetext{
9 EM 2014, momento em que se realizou a investigação de campo, a BNCC não tinha sido aprovada.

10 Tratava-se de um evento promovido todos os anos pela SME, no qual todas as escolas da rede participam. Nesse evento os estudantes fazem apresentações para a comunidade escolar.

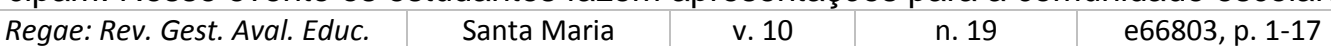

2021
} 
$\mathrm{Na}$ escola Tulipa os professores e a equipe pedagógica demonstraram um certo senso de responsabilidade pelo aprendizado dos alunos, pois verificou-se que os professores lançavam mão de metodologias diferenciadas e dos recursos didáticopedagógicos disponíveis em suas práticas pedagógicas.

Numa turma do turno da manhã a professora dedicava uma atenção especial aos alunos com dificuldade: enquanto os alunos da turma faziam uma atividade cada um em sua mesa, a professora chamou os três alunos não alfabetizados até a sua mesa, os colocou sentados próximos a ela e passou outro tipo de atividade, observando de perto e fazendo os exercícios com eles. Segundo a professora essa prática é eficaz e "surte efeitos positivos", na medida em que ela afirmou observar "progressos" na aprendizagem deles. Essa prática alinha-se à concepção de igualdade de conhecimento (Crahay, 2002) e pode ser caracterizada como uma ação de discriminação positiva, pois busca dar uma atenção especial aqueles que estavam com dificuldade.

Outra prática observada foi a oferta de aulas de reforço, no turno da tarde, para os alunos com dificuldades ou não alfabetizados. As aulas eram dadas pelo pedagogo da escola no refeitório, único lugar disponível para a realização das aulas de reforço, durante o horário regular. Ou seja, os alunos com dificuldade eram tirados da sala de aula para assistir aulas de reforço no refeitório. Embora o espaço e o horário não sejam adequados, as duas professoras do turno da tarde e o pedagogo afirmaram que estavam conseguindo obter resultados positivos e que os alunos que frequentavam as aulas de reforço teriam melhorado seus desempenhos escolares.

Essa prática escolar, embora demonstre uma preocupação com os alunos que possuíam dificuldade e embora as falas relatem efeitos positivos, ela não se alinha a ideia de igualdade de conhecimento (Crahay, 2002), pois não se trata de uma ação de ensino suplementar e, portanto, não se configura como uma ação de discriminação positiva. Tal prática, pode preencher uma lacuna no aprendizado dos alunos mas, provavelmente, irá gerar outras, pois substitui um dos processos de ensino e aprendizagem por outro num espaço escolar não adequado.

\section{Absenteísmo docente}

A ausência ou afastamento dos professores de suas atividades é entendida de forma consensual por parte dos professores e, principalmente da equipe pedagógica, como um fator que prejudica o desenvolvimento da aprendizagem dos alunos.

Durante as visitas à escola não se observou nenhuma ausência de professores nas turmas do $3^{\circ}$ ano. Segundo os depoimentos, quando um professor falta, os alunos são distribuídos em outras turmas, não necessariamente do mesmo ano escolar. Além disso a coordenação pedagógica orientava as professoras a fazerem um baú com atividades para serem realizadas pelos alunos quando eles estivessem provisoriamente alocados em outras turmas/séries. Desta forma os alunos não ficavam sem atividade. No entanto, a solução encontrada não parece ser a mais adequada, pois os alunos eram distribuídos em outras salas de aula e, ao que parece, não participavam das aulas, pois eram orientados a fazer atividades paralelas, aquelas contidas no baú. Compreende-se, com isso, que na ausência de professores, os estudantes permaneciam sem aulas. Eles apenas eram alocados em salas de aula, mas não participavam das aulas, pois desenvolviam outras atividades. 
Quando acontecia de mais de uma professora faltar no mesmo dia a diretora disse que os pedagogos entravam em sala e trabalhavam as atividades do baú. Por outro lado, quando a falta era justificada por atestado médico, a direção ligava para a SME, que enviava um professor substituto para assumir a turma durante o afastamento do professor.

\section{Colaboração docente}

A colaboração docente é um dos onze fatores elencados por Sammons (apud Brooke; Soares, 2008) como uma característica das escolas eficazes. Esse fator é frequentemente associado a um bom desempenho nas avaliações em larga escala como mostra os estudos de Pedrosa (2007) e Polon (2009).

As observações da escola permitiram verificar que os professores interagiam e trocavam ideias e informações formal e informalmente apenas com os colegas do mesmo turno. Não havia encontros e nem discussões com professores de turnos diferentes. No turno da tarde as professoras do $3^{\circ}$ ano se reuniam uma vez na semana para planejar juntas as aulas. Eram as únicas professoras com um horário programado para discutir e planejar aulas juntas. A despeito disso afirmaram não receber apoio ou orientações do pedagogo. Já as professoras do turno da manhã faziam seus respectivos planejamentos individualmente, não dialogavam entre si e não tinham conhecimento do trabalho pedagógico desenvolvido pelas demais colegas. Apesar disso, ambas disseram receber total apoio da pedagoga.

\section{Organização das turmas}

A forma de organização das turmas é um dos aspectos que ajudam a explicar as desigualdades intraescolares. Os estudos de Alves e Soares (2007), Alves e Franco (2008) e Bernado (2008) encontraram efeitos significativos das turmas sobre a variação do desempenho dos alunos.

Segundo Costa e Koslinski (2011) as escolas fazem uso de mecanismos internos que separam os alunos por habilidades ou interesses, formando classes homogêneas, que permitiriam melhores resultados médios. Na escola Tulipa as turmas eram formadas no $1^{\circ}$ ano, quando as crianças chegavam à escola, e se mantinham com a mesma composição até o $5^{\circ}$ ano.

Segundo a diretora não havia critérios de enturmação: formava-se uma turma e se houvesse demanda abria-se outra, de acordo com a ordem de chegada. No entanto, afirmou que ao longo da escolarização os alunos podiam ser remanejados por dois motivos: por sugestão do professor que, em alguns casos, recomendava que algum aluno trocasse de turma por motivos de comportamento e indisciplina; nesses casos, a diretora costumava acatar a indicação do professor; quando os pais pediam para o aluno mudar de turno. Assim, não havia reenturmação ao longo do ciclo de alfabetização. Os alunos chegavam à escola no $1^{\circ}$ ano, formavam as turmas por ordem de chegada, ou seja, por matrícula, e permaneciam na mesma turma, salvo nas duas situações relatadas pela diretora. 


\section{Qualidade docente}

De acordo com Oliveira et al (2013) o efeito da qualidade docente dos professores na aprendizagem dos alunos pode ser averiguado de acordo com dois aspectos que podem, ou não, se complementar: a formação e a distribuição desses profissionais nas turmas. Um professor pode ser avaliado como bom pela sua formação e pela sua experiência. E a alocação desse profissional nas turmas pode seguir, ou não, esses critérios.

Tradicionalmente, no Brasil, os professores escolhem as turmas em que desejam lecionar e, normalmente, os mais antigos na escola escolhem primeiro, relegando os mais novos e, provavelmente menos experientes, às turmas que não foram escolhidas pelos mais antigos. De um modo geral a alocação dos professores nessas turmas não seguia critérios objetivos, como, por exemplo, o desempenho dos alunos no Paebes-Alfa. A alocação se dava com base em critérios subjetivos, que atendiam principalmente o desejo de cada professor.

Os dois aspectos que compõe a categoria qualidade docente (Oliveira et al, 2013) foram investigados:

- Formação: todas as professoras e os pedagogos possuíam graduação e, pelo menos uma pós-graduação na área de educação. A diretora disse ter como formação o curso de Pedagogia e afirmou já ter dado aula alguns anos atrás naquela mesma escola.

- Distribuição, alocação dos professores nas turmas: a diretora alocava as professoras nas turmas de acordo com o perfil de cada um. Essa decisão era tomada pela diretora sem a participação de nenhum integrante da equipe pedagógica no processo de escolha. Entretanto, a diretora afirmou que antes de decidir a alocação dos professores nas turmas perguntava as preferências de cada uma. Apesar disso existiam algumas professoras que, segundo o depoimento da diretora, ela "não troca de jeito nenhum". Um exemplo foi observado: a professora da turma $\mathrm{C}$ do $3^{\circ}$ ano lecionava há 6 anos no $3^{\circ}$ ano escolar e a diretora não a deixava mudar de etapa, alegando que teria o perfil para lecionar no $3^{\circ}$ ano.

\section{Uso do tempo}

O uso do tempo destinado à aprendizagem é uma categoria de análise levantada por Crahay (2002) como uma das principais características referentes à igualdade de conhecimento. Alguns estudos (Slavin, 1996; Pedrosa, 2007, Carnoy, 2009) mostram a associação positiva entre o tempo efetivamente dedicado à aprendizagem e o desempenho dos alunos nas avaliações.

Segundo as professoras, os dois pedagogos e a diretora, havia um maior tempo de ensino dedicado às matérias de língua Portuguesa e Matemática. A grade de horário mostrava que havia um maior tempo dedicado às aulas dessas áreas curriculares, sendo a carga horária de Geografia, História e Ciências reduzida. Apesar disso, durante o período de coleta dos dados, verificou-se aulas de História, Geografia e Ciência nas turmas $\mathrm{B}$ e $\mathrm{C}$. Nas turmas $\mathrm{A}$ e $\mathrm{D}$ não se observou aulas dessas áreas de conhecimento.

Além disso notou-se que parte considerável do tempo escolar dedicado às atividades didático-pedagógicas era usado em função de interrupções, pausas, deslocamento dos alunos para as aulas de Educação Física e Informática, retorno do recreio e entrada na escola. Havia um ritual diário de entrada: os alunos chegavam à 
escola e se dirigiam diretamente para o ginásio, onde formavam filas e rezavam a oração do Pai Nosso. Às quintas-feiras, além da oração, havia também o canto do hino nacional. Por causa desse ritual o início efetivo das aulas acontecia cerca de 10 a 20 minutos após a chegada dos alunos à escola.

Em todas as turmas observou-se que as interrupções das aulas aconteciam por vários motivos: chamar a atenção dos alunos por indisciplina, providenciar material de trabalho, dar/receber recado da coordenação, entrada em sala de professora de outra turma solicitando alguma informação ou material pedagógico e, também, para distribuição de frutas aos alunos. Essa interrupção foi observada na turma A, quando a merendeira da escola entrou na sala de aula, cerca de 40 minutos após o horário da merenda com um cesto cheio de bananas e foi de mesa em mesa distribuindo a fruta para os alunos. Segundo explicação da merendeira muitas bananas tinham sobrado e, para não estragar, ela resolveu ir de sala em sala distribuindo-as para os alunos, professores e outros profissionais da escola. Esta pode ter sido uma cena inusitada, mas mostra que a decisão de interromper as aulas não é uma prerrogativa pedagógica restrita à direção, à coordenação pedagógica ou aos professores e que as interrupções aconteciam por motivos variados e, na maioria das vezes, não relacionados à aprendizagem dos alunos.

Havia também o uso diário de alguns minutos no final das aulas, quando as professoras encerravam as atividades didático-pedagógicas antes do horário regular, justificando que não havia mais tempo para iniciar outra atividade e, por isso, pediam aos alunos para que guardassem seus materiais e aguardassem o sinal tocar para irem embora.

\section{Participação e envolvimento dos pais nas atividades escolares dos filhos}

O relacionamento da escola com a família é apontado como um dos onze fatores elencados por Sammons (apud Brooke; Soares, 2008) das escolas eficazes. As escolas que promovem eventos de forma a chamar as famílias a se engajarem nas atividades escolares dos filhos contribuem para o bom desempenho dos alunos.

Nesse estudo esta categoria de análise foi investigada por meio das entrevistas realizadas com os profissionais da escola ${ }^{11}$. Segundo os relatos um dos maiores desafios enfrentados pela escola era a participação da família na vida escolar dos filhos. Quando a escola promovia eventos e reuniões os responsáveis participavam. Entretanto, no depoimento dos entrevistados essa participação poderia ser mais efetiva. A diretora explicou que, em sua opinião, deveria existir um engajamento maior dos pais nas atividades escolares que os alunos realizavam em casa. Segundo ela, se as famílias ajudassem os alunos nas tarefas escolares, os resultados seriam melhores. Para a pedagoga do turno da manhã as famílias não compreendiam bem a função da escola, pois viam a escola como um depósito, em que elas deixavam os filhos para poderem trabalhar e, também, para ganharem os benefícios do governo: o Bolsa Família e o Programa Mais Educação. Apesar disso, ela afirmou que as famílias eram participativas e compareciam às reuniões e plantões pedagógicos: reuniões individuais com os pais para informar sobre o desenvolvimento do aprendizado dos filhos.

${ }^{11}$ Devido aos limites e escopo da pesquisa, não se realizou entrevista com as famílias dos alunos. 


\section{Considerações finais}

À luz do conceito de igualdade de oportunidades (Crahay, 2002), este estudo procurou verificar as desigualdades de média de desempenho no Paebes-Alfa entre as turmas de uma mesma escola e, complementarmente, buscou mapear algumas características escolares que pudessem ajudar a compreender às variações dessas médias de desempenho.

Os resultados obtidos a partir dos dados do Paebes-Alfa mostram que a escola teve uma média satisfatória ao final do ciclo de alfabetização mas, que em seu interior, as turmas apresentaram oscilações na evolução da média do desempenho, de forma tal que, ao final do $3^{\circ}$ ano, algumas turmas não conseguiram alcançar um nível de aprendizagem adequado. Assim, há uma maior heterogeneidade dos resultados em leitura e escrita entre as turmas dessa escola, revelando, portanto, certa desigualdade na aquisição de conhecimentos referentes à alfabetização.

A análise qualitativa revelou alguns elementos que ajudam a compreender essa desigualdade. A turma $A$ foi a que obteve as piores médias de proficiência na avaliação do Paebes-Alfa ao fim do 3ํano do ensino fundamental. De acordo com os padrões de desempenho esta turma situou-se no padrão abaixo do básico em leitura e básico em escrita e algumas características podem ajudar a compreender o porquê desse desempenho aquém do esperado. Por exemplo, a turma $A$ tinha o maior número de alunos e a única que possuíam uma professora uma DT, ou seja, uma professora com contrato temporário. Dentre as professoras que atuavam no $3^{\circ}$ ano, era a mais inexperiente, com seis anos de atuação docente. Além disso, nesta turma se encontrava todos os alunos do $3^{\circ}$ ano que possuíam alguma deficiência. Segundo a professora, eram seis, sendo um esquizofrênico.

Nas observações das aulas verificou-se na turma A uma atividade "não tradicional" que envolvia a montagem de um puf que seria exposto em um evento promovido pela SME. A partir de um tema transversal - o meio ambiente - essa atividade não estava claramente relacionada a um conteúdo curricular específico, parecendo mais uma atividade recreativa, pois não se observou uma discussão sobre a temática do meio ambiente. A despeito disso, para a confecção do puf, foi necessário a realização de algumas contas de Matemática, todas feitas pela professora no quadro.

É possível que essas características possam ter contribuído para o desempenho insatisfatório da turma $\mathrm{A}$ no último ano do ciclo de alfabetização e significativamente inferior às demais turmas. Isto evidencia que a organização escolar e as ações pedagógicas adotadas em sala de aula podem influenciar na aquisição de conhecimentos de base e na evolução do desempenho médio mensurado pelas avaliações em larga escala, levantando características que permitam pensar sobre como a escola gere as desigualdades em seu interior.

\section{Referências}

ALBERNAZ, Ângela; FERREIRA, Francisco; FRANCO, Creso. Qualidade e eqüidade no ensino fundamental brasileiro. Pesquisa e Planejamento Econômico, Rio de Janeiro, v. 32, n. 3, 2002, p. 453-486. 
ALVES, Maria Teresa; FRANCO, Creso. A pesquisa em eficácia escolar no Brasil: evidências sobre o efeito das escolas e fatores associados à eficácia escolar. In: BROOKE, Nigel; SOARES, José Francisco (orgs.). Pesquisa em eficácia escolar: origem e trajetórias. Belo Horizonte: UFMG, 2008, p. 482-500.

ALVES, Maria Teresa; SOARES, José Francisco. Efeito-escola e estratificação escolar: o impacto da composição de turmas por nível de habilidade dos alunos. Educação em Revista, Belo Horizonte, v. 45, 2007, p. 25-58.

BERNADO, Elisângela. Composição social e cognitiva de turmas e desempenho em Leitura e Matemática: como evoluem as desigualdades educacionais? Rio de Janeiro: PUC-Rio, 2008. 202f. Tese (Doutorado em Educação). Pontifícia Universidade Católica do Rio de Janeiro.

BROOKE, Nigel; SOARES, José Francisco. Pesquisa em eficácia escolar: origem e trajetórias. Belo Horizonte. UFMG, 2008.

COSTA, Márcio; KOSLINSKI, Mariane. Quase-mercado oculto: disputa por escolas comuns no Rio de janeiro. Cadernos de Pesquisa, São Paulo, v. 41 n. 142, 2011, p. 246266.

CRAHAY, Marcel. Poderá a escola ser justa e eficaz? Da igualdade de oportunidades à igualdade de conhecimentos. Lisboa: Instituto Piaget, 2002.

CARNOY, Martin. A vantagem acadêmica de Cuba: porque seus alunos vão melhor na escola. São Paulo: Ediouro e Fundação Lemann, 2009.

DUBET, François. O que é uma escola justa? Cadernos de Pesquisa, São Paulo, v. 34, n. 123, 2004, p. 539-555.

ESPÓSITO, Yara; DAVIS, Cláudia; NUNES, Marina. Sistema de avaliação do rendimento escolar: o modelo adotado pelo Estado de São Paulo. Revista Brasileira de Educação, São Paulo, n. 13, 2000, p. 25-53.

LEE, Valerie; FRANCO, Creso; ALBERNAZ, Ângela. Quality and equality in brazilian secondary schools: a multilevel cross-national school effects study. International Review of Contemporary Sociology, New York, 2007, p.1-49.

MURILLO, Javier. Una panorámica de la investigación iberoamericana sobre eficacia escolar. Revista Electrónica Iberoamericana sobre Calidad, Eficacia y Cambio en Educación, Madrid, v. 1, n. 1, 2003, p. 1-14.

OLIVEIRA, Romulado; BAUER, Adriana; FERREIRA, Maria Paula; MINUCI, Elaine; LISAUSKA, Fabio; ZIMBARG, Renata; CASSETTARI, Nathalia; CARVALHO, Malena; GALVÃO, Fernando. Análise das desigualdades intraescolares no Brasil. São Paulo: Fundação Victor Civita, 2013.

PEDROSA, Fernanda. Clima acadêmico e promoção da aprendizagem nos anos iniciais do ensino fundamental. Rio de Janeiro: PUC-Rio, 2007. 117f. Dissertação (Mestrado em Educação). Pontifícia Universidade Católica do Rio de Janeiro.

POLON, Telma. Identificação dos perfis de liderança e características relacionadas à gestão pedagógica eficaz nas escolas participantes do Projeto Geres - Estudo Longitudinal Geração Escolar - Pólo Rio de Janeiro. Rio de Janeiro: PUC-Rio, 2009, $309 f$. Tese (Doutorado em Educação). Pontifícia Universidade Católica do Rio de Janeiro.

RIBEIRO, Vanda. Justiça na escola e regulação institucional em redes de ensino do Estado de São Paulo. São Paulo: USP, 2012. 489f. Tese (Doutorado em Educação). Universidade de São Paulo. 
SAMMONS, Pam; HILLMAN, Josh; MORTIMORE, Peter. Key characteristics of effective schools: a review of school effectiveness research. London: Ofted, 1995.

SLAVIN, Robert. Salas de aula efectivas, escuelas efectivas: plataforma de investigación para una reforma educativa en América Latina. Santiago de Chile: Preal, 1996.

Naira da Costa Muylaert Lima é professora na Pontifícia Universidade Católica do Rio de Janeiro.

Orcid: https://orcid.org/0000-0001-5161-0501.

Endereço: Rua Marquês de São Vicente, 225 - 22451-900 - Rio de Janeiro - RJ Brasil.

E-mail: naira@puc-rio.br.

Critérios de autoria: a autora concebeu a ideia, coletou, descreveu e analisou os dados apresentados. A autora contou com a colaboração de integrantes do Laboratório de Avaliação da Educação - Laed/PUC-Rio -, em especial da professora dra. Alicia Bonamino - PUC-Rio - para a concepção, execução, análise e interpretação dos dados.

Recebido em 20 de julho de 2021.

Aceito em 29 de outubro de 2021.

(c) (i) $(9$ 